\title{
The Application of the Theory of Embodied Cognition in Online Science Teaching in Primary Schools
}

\author{
Zhenqiang Wang ${ }^{1, *}$, Jingbiao $\mathrm{Xu}^{2}$ \\ ${ }^{1}$ Nanjing Xiaozhuang University Affiliated Primary School, Nanjing, Jiangsu 211171, China \\ 2 Nanjing Xiaozhuang University, Nanjing, Jiangsu 211171, China \\ *Corresponding Author: 63112981@163.com
}

(Received: 08/04/2020; Accepted: 09/08/2020; Published: 09/29/2020)

DOI: https://doi.org/10.37906/real.2020.7

\begin{abstract}
Embodied cognition is a theory that studies the features of cognition that are formed through the experience of one's body in a specific environment. It unveils that the body, via action and gestures, can be a powerful tool to enhance understanding and learning. In this paper, the theory of embodied cognition is introduced, and incorporated to the online elementary science curriculum, where the teachers are encouraged to involve physical interactions and participations during teaching, so that the students can better understand and master the scientific concepts. This new instructional method is shown to improve students' scientific literacy and the quality of online teaching.
\end{abstract}

Keywords: embodied cognitive theory; online; elementary school science teaching; inspiration

\section{Introduction}

With the advent of cognitive linguists G. Lakoff and M. Johnson's famous book "The Philosophy of the Flesh: Physical and Mental Intelligence and Its Challenge to Western Thought", it marked the "second generation" with the emergence of "cognitive science", the body has a huge influence on the mind (Li, 2008). Whether studying in school, exerting creativity at work, or succeeding on the playing field or on the stage, there are countless examples that can prove that physical experience always affects our thinking. The power of the body can be summarized as: using the body as a tool to feel better, a tool to help thinking, and a tool to use the body to cultivate the mind and understand the experience of others (Beilock, 2019). There have been many offline teaching practices and researches in the theory of embodied cognition, but research on online science teaching in elementary schools is rare. Combining the basic, practical, and comprehensive characteristics of elementary school science courses, the application of embodied cognitive theory to elementary school science online teaching will be of special significance.

\section{An overview of embodied cognition theory}

The embodied cognition haircut originated from people's attention to "physical philosophy", developed from people's research on "physical phenomenology", and became famous in the concept of "body schema" and "body synthesis" of "existentialist philosophy". Theories such as metaphor, perceptual symbols, mirror neurons, and technological phenomenology are its foundation, which emphasizes that cognition is the result of the coupling of the body, mind, and environment. The mind is rooted in the body, and the body is rooted in the environment. The result of the interaction between the mind, body and the environment is 
meaningful learning of knowledge. (Ye, 2015) The theory emphasizes the characteristics of embodiment, contextuality, and generativeness.

\section{Cognition is embodied}

Cognition comes from the body. Cognition is not a closed activity independent of the body, but has a "physical (body) nature". The embodiment of cognition is to implement the mind "floating in the void" into the human's actual experiences, and then link the experiences to the human body (including the brain), so all life phenomena are related to the advanced activities that are including cognition, emotion, language, and so on. They are woven together and become different manifestations of human reason. (Li \& Mo, 2011) The embodied expression of thinking, and the occurrence of cognition not only involves the participation of body structure, neural structure, sensory and motor systems, but also the embedding of the body's feelings, experiences, and experiences. Psychologist E. Thelen pointed out: "Cognition originates from the interaction between the body and the world, and the mind relies on various experiences of the body. These experiences come from the body with unique perception and motor abilities, and these abilities are inseparably linked together to form a memory. The body in which emotions, language and other aspects of life are woven together." (Thelen, Schoner, Scheier \& Smith, 2001) Therefore, the body is the basic premise for cognitive activities. The generation of cognition comes from physical practice activities. This activity consists of three judging from the following aspects: First, the individual is the main source of cognitive formation by participating in practical activities; second, the physical and mental state affects the process and cognitive content of cognition; third, reflecting on the body based on one's own situation. The behavior of cognition, that is, reflective cognition. In short, "embodies" is not only a physical body, but also a mental and spiritual body.

\section{Cognition is contextual}

Environment that expresses a criticism of the objective universality and inevitable validity of epistemology, and that cognition is not a universal and neutral behavior that is out of context, context, and circumstances, but is embedded in the environment. Dialogue with the situation, the brain, body, and environment form a dynamic unity. "The influence of environmental factors on cognition is not only causal, but also constitutive. Environmental conditions not only affect cognition, but also become a component of cognitive function." Therefore, "cognition is not a priori logical ability is a contextual process of continuous evolution." (Ye, 2017) As the psychologist A. Clark said: "The mind is not a special inner place where inner models and representations gather, but a brain, body and environment. The activities and processes of an integrated and intertwined complex system." (Clark, 1999) Individual behaviors have a certain behavioral background and cannot occur without being separated from the social background and the individual's environment. Individuals' cognitive behaviors will be affected by the social context. Family, and personal background produce cognitive behavior. Different environments produce different cognitive behaviors. The environment is an effective medium for understanding the individual's cognitive status, and the indepth analysis and thinking of the individual's cognition can lead to in-depth research on the individual. The situation is based on the environment, creating a situation that has an image, highlights the characteristics of the discipline, and researches in a real environment, and at the same time stimulates the emotional situation of the students. In short, the environment is based on the origin of the creation of the situation, and the situation is the generation and development of environmental teaching. 


\section{Cognition is generative}

It shows that the cognitive process is not mechanical, linear, and decisive, but a dynamic system generated by the coupling of various factors from the brain, body, and environment. In this regard, F. Varela pointed out: "Knowledge is not a pre-given mind's representation of the pre-given world. Cognition is rather on the basis of the history of the diverse effects of existence in the world'. The generation of the world and the mind."(Varela, 2010) Individual cognition is constantly developing, dynamically developing, and in a state of constant change and development. In short, the development of cognition has a dynamic mechanism, and the process of cognition is generated through the mutual influence and interaction of the brain, body, and environment.

\section{Features of Online Science Teaching in Primary Schools}

According to the embodied cognition theory the acquisition of knowledge is formed by body-based cognition. The body is the core part of individual cognition, and the body provides cognitive content for individual cognition. The elementary school science curriculum standard points out: elementary school science curriculum is a basic course, practical course, and comprehensive course. Compared with traditional teaching, online elementary science teaching has its own unique advantages.

\section{Multi-source information}

\section{Diversified learning resources}

With the development of the information age, online learning resources are diversified. There are text materials, video materials, music materials, graphic materials, virtual experiments, and so on. Primary school science is a practical and comprehensive course, and you can find some resources online for learning. For example, for the study of video materials such as scientific experiments and scientific production, you can also search for materials based on exploratory activities such as task lists and small research projects for inquiry learning. You can follow some scientific micro-public accounts and scientific websites for learning.

\section{Diversified practical materials}

The practical materials are diverse. When selecting experimental materials, we must fully consider the materials around the students. The materials for the experiment should be simple, feasible and relatively easy to find. For example, candles, glasses, balloons, rice, chopsticks, plastic bottles, paper, and so on. These materials are all the materials around, the experiment cost is relatively low, and it can also meet the teaching preparation before the experiment. The process of preparing materials for students is also a kind of learning. They observe, compare, and choose appropriate materials for experiments. For example, in the teaching activity of "Building High Towers", students are given requirements for high towers, and students choose suitable materials around them for practical activities according to the height requirements. 


\section{Multiple convenience}

1. The convenience of pre-learning

Pre-learning is a self-learning construction process of students' independent learning and teachers' enlightenment and guidance. Online pre-learning of science in elementary schools focuses on cultivating students' good habits of independent thinking and independent learning, and then preparing for scientific inquiry. The 2017 version of the compulsory education elementary school science curriculum standard proposes that in order to cultivate students' scientific literacy, teachers should provide students with diversified learning opportunities. Such as the opportunity to explore, the opportunity to comprehensively apply knowledge to solve real situational problems, the opportunity to discuss and debate, the opportunity to care about issues related to environmental resources, and so on. The focus is on students' independent thinking and self-study and inquiry ability, and they can conduct research learning according to different learning content and topics, which reflects creative and innovative learning. Online learning resources are rich and diverse, which is convenient for students to conduct individualized and exploratory learning on different topics.

\section{Convenient learning time}

According to the statistics of online teaching carried out by 1200 students of the whole school in the previous period, $77.4 \%$ of the students' study time is mainly concentrated in the morning from 9:00 to 11:00, and $15.4 \%$ of students are concentrated in the afternoon. Of the time, $7.2 \%$ of students study at night. Different students have different needs for online learning. Online learning provides students with the convenience of learning time, and students can arrange time for learning according to their own time. The time arrangement is more flexible, which provides more convenience for students to study to a certain extent.

\section{Diverse learning methods}

The learning methods of elementary school science online courses are diverse. Inquiry learning is an important way for students to learn science. Hand-brained science is one of the important differences between elementary school science classes and other classes. In many cases, students have to learn science by doing them by hand, such as doing experiments, making models, observing, measuring, planting and raising. These activities are not only the learning methods that students like, but also the important experiences which support students to understand scientific concepts. Hands-on activities should not be purely operational activities, but should also be combined with brain-work. Thinking at the same time can make the two support each other and complement each other. (China, 2017) The diversity of online learning resources and materials determine the diversity of learning methods. Students can carry out different types of scientific inquiry activities according to their hobbies. For example, these activities such as science experiments, science productions, science researches, and science fiction paintings can also use science popularization network resources, science micro-public accounts for learning, and online science popularization venues to choose their own way to learn. 


\section{Multi-directional interaction}

\section{Personalized learning}

Students are the main body of learning, and learning is the student's own business, and others cannot replace it. Due to the differences of the students themselves, the different families and environments where the students live, the interests of the students are also diverse. Elementary school science online teaching provides students with content in different fields such as material science, life science, earth and universe science, technology and engineering. Students can choose what they are interested in based on their own hobbies to carry out exploratory learning activities. Students can communicate with the teacher at any time for their own research, and the teacher will provide one-to-one personalized guidance based on the students' inquiry activities.

\section{Timely assessment}

The implementation of assessment is to understand the performance and problems in the learning process. Online elementary science teaching assessment is more timely than traditional. When students complete the exploratory experiment activities, they can take photos or make videos of the recording process and send them to the teacher in time. The teacher can learn about the students' learning situation and whether they are interested in the experiment exploratory activities according to the students' photo or video homework feedback. Provide timely encouragement and guidance to students.

\section{Application of embodied cognition theory in online science teaching in elementary schools}

The embodied cognition theory believes that the body is the foundation and core of individual cognition, and that individual cognition is the cognitive behavior obtained after the body participates in practical activities. Therefore, based on the enlightenment of embodied cognition theory, the following two aspects should be paid attention to when implementing online elementary science teaching.

\section{Online pre-learning, realizing the student's dominant position, and improving learning initiative}

Online pre-learning highlights the main role of students in learning. In a task-driven way, students use their original knowledge and experience to learn, which improves their initiative in learning. This is specifically reflected in the online task assignment link, online student self-study link, and online teacherstudent inquiry link.

1. With the continuous deepening of the new curriculum reform in the online task assignment link, teaching methods such as "study first and then teach" and "student-oriented" have entered the classroom. Online pre-learning is the driving force for the online task list. Students use their original knowledge and experience to conduct various investigations, research, reflections and other ways to interpret new knowledge in a personalized way, which not only improves students The ability to learn independently, and at the same time improve students' enthusiasm for learning. For example, the teaching task of "Building a Bracket" is higher than anyone else. There are several requirements for this task: 1) No less than $60 \mathrm{~cm}$; 2) No collapse during testing; 3) No more than 30 minutes of production time. Students should prepare and design for experimental materials and construction drawings. And to develop the habit of 
selecting materials, design drawings, recording, and evaluation by yourself is very important for future scientific investigations. In the process of scientific experiment exploration, students guide students to observe and think, analyze the causes, explain some scientific phenomena in life, and improve students' cognitive skills.

2. Mr. Tao Xingzhi, a great people's educator in the online student self-study session, puts forward: Today's students are the future citizens, and the citizens needed in the future. We need to be able to selfgoverning citizens as well as self-governing students. According to the statistics of the online teaching of 1,200 students of the whole school in the previous period, $29.9 \%$ of the students need the company of their parents, and $70.1 \%$ of the students do not need the company of their parents. According to the data, it is found that nearly one-third of students need the company of their parents to complete their studies. Most students can complete their studies independently. By comparing the proportion of students in different grades and whether they need parent company, $29.9 \%$ of the students who need parent company are from lower grades, accounting for $87.9 \%$ of the total number of lower grades, which is very different from the physical and mental development characteristics of lower grade students. The low grade students have insufficient self-management ability and need parental supervision for learning. In the online self-study process, students need to plan their own time, realize self-supervision and self-management, which helps to improve students' independent exploration ability.

3. Online teacher-student inquiry Merleau-Ponty believes that humans perceive the world with their bodies, which means that skills are also the same. It is through the rotation of the head and the back and forth movement of the body that constitute the depth perception information processing and learned. Such as experimental skills, computer skills, dance skills. Moreover, the fundamental way of encountering things that Hagerdell strongly advocates is "hand-based", and through examples such as learning how to hammer a nail, it illustrates that the spatiality of the body is the fundamental way for us to learn skills. (Li \& Mo, 2011) Online teacher-student inquiry is mainly reflected in the following aspects: First, pay attention to personal participation in scientific inquiry. Inquiry is about physical experience, and "knowing the periscope" is essentially different from "knowing the periscope". The process of students' inquiry is not only the acquisition of skills, but also the process of the individual's deepening knowledge and understanding of the periscope. Second, pay attention to the level of inquiry. Scientific inquiry skills require different requirements for different students. For example, controlled experiments are the basis of scientific inquiry. It is relatively easy to design controlled experiments, control variables and other skills, but "use mathematical methods to process and interpret data, make reasonable judgments based on evidence, use accurate terms and charts to introduce research methods and results, and clarify views "Competences such as those are more demanding. (Ye, 2017) Students will inevitably encounter various problems in the inquiry activities, which requires the students to actively communicate with the teacher to realize joint inquiry.

\section{Online situational teaching to stimulate students' emotional experience and improve learning effects}

The creation based on the real situation will help stimulate students' interests in inquiry and enthusiasm for learning. Online teaching gives full play to the advantages of online teaching and gives full play to the initiative of students in learning. Provide children with opportunities to think, experience activities, display and communication opportunities, innovative applications to promote the improvement of students' scientific literacy ability. 
1. Create scenes online, embodied and feel the goals Create scenarios online, and feel the teaching goals physically and mentally. According to the characteristics of online learning and the characteristics of elementary school science teaching, a teaching situation is created. In the created situation, students use their body and mind to feel the setting of teaching goals. For example, the teaching activity of "Lifting Rice with Wooden Sticks". Presents the experiment of raising rice with wooden sticks. When students see the photos, they will be immersed in the scientific experiment and feel the joy of success.

2. Ask questions online and think about the problem in person. Einstein proposed: Finding a problem is more important than solving one. The starting point of the scientific inquiry process is to discover problems. Online teaching also allows students to observe phenomena and then discover problems for in-depth scientific inquiry. In studying the teaching content of "A4 Paper Load Bearing", the teacher asked: How powerful is A4 paper? For this problem is relatively large, it must be resolved. How can the load-bearing capacity of A4 paper be changed? Students will think of changing the shape to combine the circles, triangles, and other shapes are seen in life. Do in-depth research on this issue? Which shape has the greatest bearing capacity? It is necessary to conduct a comparative experiment. Finally, it was found that the cylindrical shape had the largest weight. How much does it bear? Next, challenge 1 person, about 35KG. Students conduct experimental exploration and experience it for themselves. Some students can succeed, and some cannot succeed. In this case, students can combine their own experimental process to think and summarize, evaluate and summarize their own investigations, or invite parents to participate in experimental investigations and evaluate together. Finally, send the research records and photos or video materials to the teacher through QQ for review. The teacher will comment on the materials submitted by the students. You can choose some good videos or pictures to publish through the school's official website or Wechat public account. Under such circumstances, it stimulates students' desire and enthusiasm for inquiry, and at the same time cultivates the scientific spirit of seeking truth from facts and dare to question.

3. Online guidance, embodied experience activities. Scientific inquiry activities are not always successful. In the experiments of students carrying out the load-bearing experiments on A4 paper, some students can successfully complete the experiment, and some students have not succeeded in the experiment. For those who succeed, find the way to succeed, and for those who fail, find the reason. First, observe the number of cylinders, the placement of the cylinders, the height of the cylinders, and so on; secondly, observe the method of the station. Students must give careful guidance in every aspect of the experience activity.

4. Online summary, personal display and communication Based on the timely characteristics of online learning evaluation, for online learning, students' inquiry activities should be displayed, exchanged, and summarized and evaluated. In the course of scientific exploration activities, students communicate with their parents, show off their successful experiments, and take some successful photos or videos, and so on. Summarize your own successful experience in the exploration activities, find out the reasons for the failure, and carry out the experimental challenge again.

5. Online expansion and improvement of embodied migration. Embodied migration is an application expansion of learning content and an improvement to consolidate learning content. Science comes from life and returns to life. Online teaching should also take into account the learning of extended tasks. For example, in the teaching content of the lesson "The Production of Sound", students explored the motion trajectories of different objects such as rulers and vocal cords, and concluded that sound is produced by the vibration of the object. Students only explore a few different objects. There are thousands of different sounds in nature, such as the buzzing of bees, birds, wind, and rain. Students are required to search for 
different sounds in nature and observe these objects. The phenomenon when it occurs. Through such activities, students have a deep understanding of the principles of sound production.

\section{Conclusion}

The embodied cognition theory has accumulated some experiences in the online elementary school science teaching. It has its own characteristics in the embodiment of scientific concepts and the embodied nature of scientific inquiry, which is worth learning. The embodied cognition theory promotes physical and mental development based on the coupling of body, situation, and mind. Elementary school science education is practical and comprehensive. How can online teaching give students more in-depth research on course content, experimental exploration, observation records, and so on? How to effectively improve the scientific literacy of students? It is necessary to formulate a set of comprehensive online education and teaching indicators as the basis for evaluating student development.

Conflicts of Interest: The authors declare no conflict of interest.

\section{References:}

A. Clark. (1993).An Embodied Cognitive Science. Trends in cognitive science. (3), 345-351.

Beilock.(2019). Embodied cognition: how the body affects thought and behavior(Chinese Ed.). Translated by Li P. Beijing. China Machine Press.177-178.

Li, Q. W. (2008).Cognitive Revolution and the second Generation of Congnitive Science (Chinese Ed.). Journal of Psychology (12),1306-1327.

Li, Y. Y., \& Mo, Y. H.(2011). Research on the educational significance and potential value of embodied cognition (Chinese Ed.). Journal of Guangxi Teachers College (Natural Science Edition) (9), 110-113.

Ministry of Education of the People's Republic of China. (2017). Curriculum Standards of Science in elementary schools (Chinese ed.). Beijing. Beijing Normal University Publishing Group.

Thelen,E.,\&Schoner,G.,\&Scheier,C.,\&Smith,B,.The dynamics of embodiment: A field theory of infant preservative reaching. Behavioral and Brain Sciences, 2001 (24):1-8.

Varela et.( 2010). Body and mind: Cognitive Science and human experience (Chinese Ed.).Translated by Li Hengwei et. Hang Zhou. Zhejiang University Press.

Ye.H.S.(2017). The principle and application of embodied cognition (Chinese Ed.). Beijing. Commercial Press.51.

Ye.H.S.(2015). Body and learning: embodied cognition and its challenge to traditional educational view (Chinese Ed.). Educational Research (4), 104-114. 